\title{
Auspicious Birth Dates among Chinese in California
}

\author{
Douglas Almond ${ }^{\mathrm{a}}$, Christine Pal Chee ${ }^{\mathrm{b}}$, Maria Micaela Sviatschii, ${ }^{\mathrm{c},}$, Nan \\ Zhong $^{\text {d }}$ \\ ${ }^{a}$ Department of Economics \& School of International and Public Affairs, Columbia \\ University, New York, NY, USA \\ ${ }^{b}$ Department of Veterans Affairs, Menlo Park, CA, USA \\ ${ }^{c}$ Department of Economics, Columbia University, New York, NY, USA \\ ${ }^{d}$ School of International and Public Affairs, Columbia University, New York, NY, USA
}

\begin{abstract}
The number eight is considered lucky in Chinese culture, e.g. the Beijing Olympics began at $8: 08 \mathrm{pm}$ on 8/8/2008. Given the potential for discretion in selecting particular dates of labor induction or scheduled Cesarean section (C-section), we consider whether Chinese-American births in California occur disproportionately on the 8th, 18th, or 28th day of the month. We find $2.3 \%$ "too many" Chinese births on these auspicious birth dates, whereas Whites show no corresponding increase. The increase in Chinese births is driven by higher parity C-sections: the number of repeat C-sections is $6 \%$ "too high" on auspicious birth dates. Sons born to Chinese parents account for the entire increase; daughter deliveries do not seem to be timed to achieve "lucky" birth dates. We also find avoidance of repeat C-section deliveries on the 4th, 14th, and 24th of the month, considered unlucky in Chinese culture. Finally, we replicate earlier work finding that Friday the 13th delivery dates are avoided and document a particularly large decrease among Chinese. For Whites and Chinese in California, mothers with higher levels of education are particularly likely to avoid delivering on the 13th.
\end{abstract}

\footnotetext{
*Corresponding author

Email address: mms2241@columbia.edu (Maria Micaela Sviatschi)
}

Preprint submitted to Economics \& Human Biology

May 8, 2015

(C) 2015. This manuscript version is made available under the Elsevier user license http://www.elsevier.com/open-access/userlicense/1.0/ 
Keywords: superstition, Chinese, eight, California, birth date.

JEL: I1, Z1

\section{Introduction}

Cultural preferences can exert a persistent effect on the fertility decisions of Asian immigrants to the West (Dubuc and Coleman, 2007; Almond and Edlund, 2008; Abrevaya, 2009). Following earlier work on sex selection in Asian

5 countries, excess males births were found among Asian immigrants to Britain, particularly at higher parities (Dubuc and Coleman, 2007). In the US, excess male births among Asian sibships is driven by families where the first birth(s) are exclusively female (Almond and Edlund, 2008; Abrevaya, 2009). In the 2000 US Census 5\% sample, having a son is $50 \%$ more likely than the biological norm after two daughters when parents are of Chinese, Korean, or South Asian race (Almond and Edlund, 2008). The authors interpret these patterns as driven by conscious decision making by parents (Dubuc and Coleman, 2007; Almond and Edlund, 2008; Abrevaya, 2009).

A potentially more benign cultural preference concerns auspicious dates of birth. For reasons expounded elsewhere (Fortin et al., 2014), the number eight is considered lucky by many Chinese, and 4 unlucky. Birth dates falling on the 8th, 18th, or 28th day of the month can readily be achieved through a 
variety of means, including choosing the date of labor induction and C-section (or postponement thereof). Likewise scheduling C-sections (or inductions) on the 4th, 14th, or 24th might be declined by parents in favor of adjacent dates. To our knowledge, it has not previously been considered whether births by Chinese are skewed to achieve an eight (or avoid a four).

Previous work has considered whether births are timed vis a vis auspicious birth years according to the Zodiac calendar (Kaku and Matsumoto, 1975; Goodkind, 1996; Rohlfs et al., 2010; Do and Phung, 2010). Conception timing and abortion play a large role in governing the effects for birth year, but cannot reliably achieve the "fine tuning" of birth date considered in this paper. Thus, the mechanisms and consequences may differ. Additionally, whereas the superstitions regarding birth years are thought to be gender specific ("girls born ${ }_{30}$ in a specific astrological year are regarded as less desirable" (Do and Phung, 2010), usually the 1966 birth year), the Chinese eight and four superstitions per se should be gender neutral. Manifestation of these superstitions, however, may be gender-specific in the context of son preference among some Chinese Americans, which we consider below. Additionally, birth frequency and birth outcomes have been shown to vary by season (Lam and Miron, 1991; Currie and Schwandt, 2013; McKinnish et al., 2014) in developed countries.

By considering short-term changes in the probability of delivery method among Chinese, Lo (2003)'s analysis of births in Taiwan in 1998 is closest to our own. Lo (2003) found that the C-section rate was $14 \%$ higher on "auspicious dates", where "auspicious" was not defined using $8 \mathrm{~s}$ as here but rather "traditional cosmology and astrology" for determining dates "suitable for marriage". The extent to which the number of births were skewed to occur on such dates was not explicitly considered. Lin et al. (2006) found C-section deliveries were reduced in Taiwan during the "ghost month" of lunar July, when major 45 surgical procedures may be considered inauspicious. To our knowledge, it has not been considered whether Asian immigrants to the West show a preference for delivering on specific auspicious birth dates.

Previous research has found short-term manipulations to achieve desired 
dates of delivery among non-Chinese. Births drop 2-4\% during obstetrics conferences (Gans et al., 2007), suggesting accommodation of physician schedules. Date discretion is also observed near the end of the calendar year, which confers a tax advantage for parents relative to birth in early January (Dickert-Conlin and Chandra, 1999). Likewise, births were delayed in Australia to receive a tax bonus (Gans and Leigh, 2009). Additionally, previous work has considered whether certain dates considered unlucky in Western cultures are avoided. In Australia, there are $7.7 \%$ too few births on Friday the 13th (Gans and Leigh, 2012). In the US, the number of births fell $11 \%$ on Halloweens from 1996-2006 and increased 5\% on Valentine's Days (Levy et al., 2011). Additionally, environmental factors may also affect birth timing in the absence of deliberate behavior, e.g. Bauer et al. (2013) on sunspot activity.

There is an extensive literature documenting variation in medical treatments that depart from clinical indication, including elective C-section (Minkoff and Chervenak, 2003) or cesarean delivery on maternal request (CDMR). One motivation for CDMR is the "desire to plan/time delivery" (Ecker, 2013). Among these non-clinical determinants of delivery method or delivery timing, achieving "auspicious" birth dates may be particularly difficult to rationalize from the perspective of public health. That said, if there is an increase in the number of C-sections and births on auspicious dates, it is not clear whether it is the health care provider or the parents who drive such an increase (Gans and Leigh, 2012). To address this point, we will consider whether fetal gender affects the likelihood of having an auspicious birth date. Often through prenatal diagnostic ultrasound, gender is routinely revealed to parents prior to delivery in the US. Is achieving an auspicious date more likely when that child is male? Given previous findings of parental preferences for sons among Asian immigrants to the US, parents may be more keen to achieve auspicious dates for their sons. Unless healthcare providers likewise seek to deliver males (but not females) on auspicious dates, it might suggest that it is parents (not providers) who are 
behind the skewed birth dates. ${ }^{1}$

\section{Methods} for both mothers and infants.

The initial dataset contains $6,762,921$ births. We restrict the analysis to those births where the mother's race is White or Chinese ( $82 \%$ and $2 \%$ of Cali-

\footnotetext{
${ }^{1}$ Unfortunately, physician race is not available in the data and we will not be able to explore to what extent Chinese providers are driving the skewed birth dates.
} 
of records have missing baby's gender. We exclude both from our analysis.

\subsection{Statistical Analysis}

For each date, we calculate the number of births by baby's gender, mother's race (White or Chinese), and mother's education. We do this for four categories of births: all births, births by primary C-section (mother's first C-section), births by repeat $\mathrm{C}$-section (mother's subsequent $\mathrm{C}$-section), and births where there was an induction of labor. For each date (defined by month, day, and year), we calculate the number of births by baby's gender, mother's race (White or Chinese), and mother's education. We do this for four categories of births: all births, births by primary C-section (mother's first C-section), births by repeat C-section (mother's subsequent C-section), and births where there was an induction of labor. Our data spans 1991-2002, so we calculate the number of births on 4,383 different dates (365 dates for 9 years and 366 dates for 3 leap years). We conduct multivariate regression analysis to test for date shifting. In all analyses we include year $(y)$, month $(m)$, and day of the week (DoW) fixed effects and main holidays effects (New Year's Day, Memorial Day, Fourth of July, Labor Day, Thanksgiving, Christmas, Christmas Eve and New Year's Eve) in regressions of the form:

$$
\begin{aligned}
\text { Log\#births }_{y, m, D o w}= & \beta_{1}+\beta_{2} \text { Contains }_{y, m, D o w}+\beta_{3} \text { Contains }_{y, m, D o w} \\
& + \text { Holiday }_{y, m, D o w}+\gamma_{y}+\theta_{m}+\kappa_{D o w}+\varepsilon_{y, m, D o w}
\end{aligned}
$$

We are interested in estimates of $\beta_{2}$ and $\beta_{3}$, the coefficients on variables 125 for whether day of month contains an 8 or 4 (respectively). We run separate regressions for Whites and Chinese. ${ }^{2}$

\footnotetext{
${ }^{2}$ In alternate specifications, we define the dependent variable to be the number of births. The results are qualitatively similar and reported in Appendix Tables A1 and A2.
} 


\section{Results}

We begin by plotting the fraction of births that are C-sections by the day of the month (1-31), removing holiday effects, for Chinese and Whites in Figures 1 and 2 below. Overall, about 22\% of deliveries are by C-section for Chinese and Whites. Repeat C-Sections are roughly $6.5 \%$ of Chinese deliveries and 8.5\% of White deliveries: the mean difference emerges for repeat C-sections because Chinese fertility is lower (and thereby higher parity birth less likely). For Chinese, we see that the 8th, 18th, and 28th days of the month are each associated with an increase in the rate of repeat C-sections (vertical lines). We see no corresponding pattern of increases on these 8 dates for Whites. For both Whites and Chinese, we see a large drop in the fraction of repeat Csection births falling on the 13th of the month (dash-dot vertical lines), a pattern previously found elsewhere (Gans and Leigh, 2012; Levy et al., 2011; Miller, 2014). Our hypothesis does not explain all of the day-to-day variation shown in the figures (e.g. the increase in Chinese repeat C-section deliveries on the 15th of the month). In addition, we lose some precision for the 31st since it is identified by seven, rather than twelve, months.

To assess the statistical significance of these patterns, we report regression results in Table 1 (while controlling for the time effects described above). These regression results likewise indicate that Chinese births in California disproportionately occur on the $8 \mathrm{~s}$ and furthermore that this skewing is statistically significant. Column 1 shows a 2.3\% excess in births falling on the 8 s. Interestingly, this behavior is concentrated among male births. Column 2 shows a $4.1 \%$ excess in male births on dates with an 8 . We also see a larger magnitude response for deliveries by $\mathrm{C}$-section. There are approximately $7 \%$ "too many" repeat male C-sections on the $8 \mathrm{~s}$ (column 4). There is also some evidence of too few repeat C-sections on the $4 \mathrm{~s}$ (roughly a $5 \%$ drop). Repeat C-sections for girls do not show corresponding pattern. Turning to the 13th, there is substantial evidence of avoidance among Chinese for male and female births alike. There are about $14 \%$ too few $\mathrm{C}$-section births on 13th for both boys and girls, and suggestive 


\section{evidence of an additional effect of the 13th when it falls on a Friday. ${ }^{3}$}

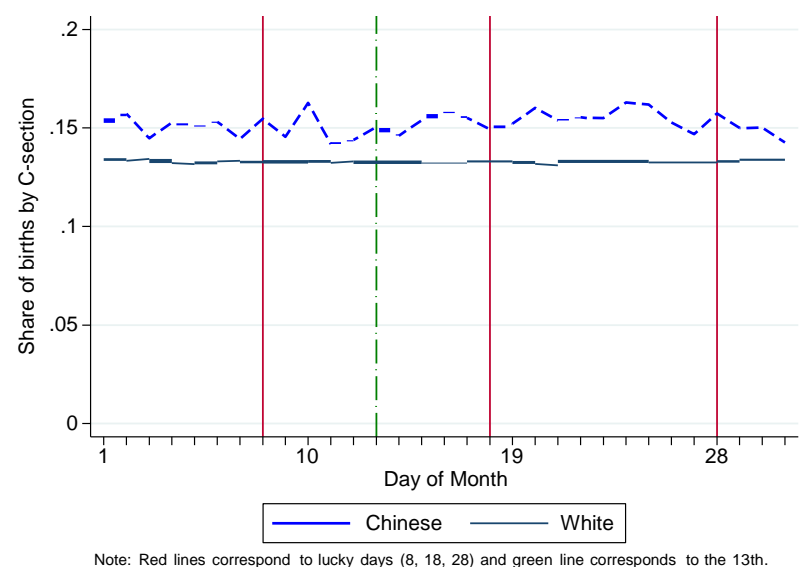

Figure 1: Share of births by C-section, by day

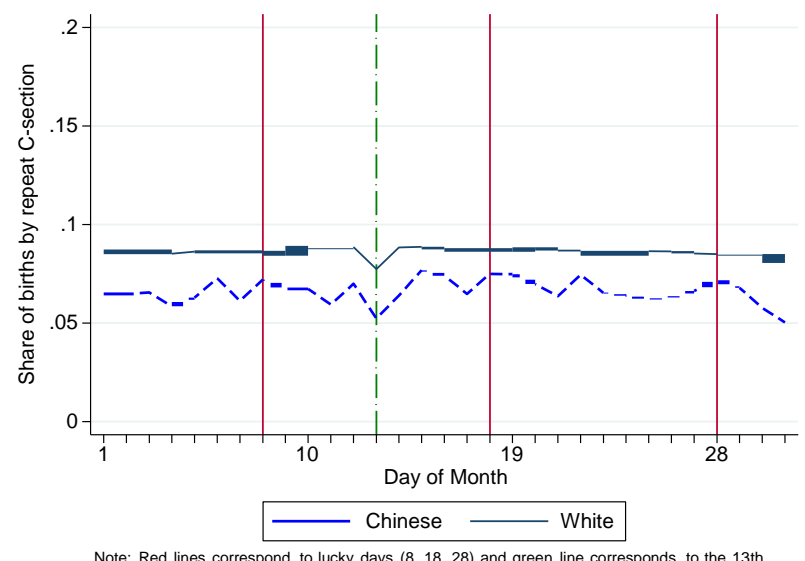

Figure 2: Share of births by repeat C-section, by day

\footnotetext{
${ }^{3}$ We also check the robustness of these results by clustering the standard errors at the digit level following wild cluster bootstrap. The results under this clustering lead to smaller p-values. Results are available upon request.
} 
Table 1: Regression Estimates: Log Number of Chinese Births by Day

\begin{tabular}{lccccc}
\hline \hline & $(1)$ & $(2)$ & $(3)$ & $(4)$ & $(5)$ \\
\hline Contains8 & $0.023^{\star \star}$ & $0.041^{\star \star \star}$ & 0.007 & $0.069^{\star \star}$ & 0.016 \\
& $(0.010)$ & $(0.014)$ & $(0.015)$ & $(0.029)$ & $(0.029)$ \\
Contains4 & -0.016 & -0.001 & -0.024 & $-0.052^{\star}$ & -0.033 \\
& $(0.010)$ & $(0.014)$ & $(0.015)$ & $(0.031)$ & $(0.032)$ \\
Thirteen & $-0.062^{\star \star \star}$ & $-0.047^{\star}$ & $-0.062^{\star \star}$ & $-0.137^{\star \star}$ & $-0.138^{\star \star}$ \\
& $(0.018)$ & $(0.025)$ & $(0.026)$ & $(0.055)$ & $(0.058)$ \\
Friday13 & -0.037 & -0.099 & -0.001 & -0.154 & -0.245 \\
& $(0.047)$ & $(0.067)$ & $(0.070)$ & $(0.161)$ & $(0.175)$ \\
\hline Observa- & 4,383 & 4,383 & 4,382 & 2,813 & 2,684 \\
tions & & & & & \\
Number of & 141,541 & 72,519 & 67,005 & 4,952 & 4,493 \\
births & 0.255 & 0.147 & 0.142 & 0.075 & 0.061 \\
R-squared & Chinese & Chinese & Chinese & Chinese & Chinese \\
Mother & All & Boys & Girls & Repeat & Repeat \\
Birth & Births & & & CS-Boy & CS-Girl \\
& &
\end{tabular}

All models include year, month, and day of the week fixed effects and main holiday effects.

Robust standard errors in parentheses.

${ }^{\star * *} p<0.01,{ }^{* *} p<0.05,{ }^{*} p<0.1$

For Whites, there is no corresponding pattern with respect to the $8 \mathrm{~s}$ and $4 \mathrm{~s}$. None of the point estimates reported in first row in Table 2 are distinguishable from 0 (and are under 1\% in magnitude). There is, however, a consistent reduction in births on the 13th of the month. There also seems to be an even stronger avoidance of Friday the 13th among deliveries that were repeat C-section. We find a $20-25 \%$ drop in C-sections for Friday the 13th (combing coefficients for the 13th and Friday the 13th), an aversion which appears to be shared by males and females alike. 
Table 2: Regression Estimates: Log Number of White Births by Day

\begin{tabular}{|c|c|c|c|c|c|}
\hline & (1) & (2) & (3) & (4) & (5) \\
\hline Contains8 & $\begin{array}{c}0.002 \\
(0.002)\end{array}$ & $\begin{array}{c}0.002 \\
(0.004)\end{array}$ & $\begin{array}{c}0.004 \\
(0.004)\end{array}$ & $\begin{array}{c}-0.008 \\
(0.010)\end{array}$ & $\begin{array}{c}0.008 \\
(0.010)\end{array}$ \\
\hline Contains4 & $\begin{array}{l}0.004^{*} \\
(0.003)\end{array}$ & $\begin{array}{c}0.003 \\
(0.004)\end{array}$ & $\begin{array}{l}0.008^{*} \\
(0.004)\end{array}$ & $\begin{array}{c}0.003 \\
(0.010)\end{array}$ & $\begin{array}{c}0.011 \\
(0.010)\end{array}$ \\
\hline Thirteen & $\begin{array}{c}-0.022^{\star * \star} \\
(0.004)\end{array}$ & $\begin{array}{c}-0.018^{\star \star} \\
(0.007)\end{array}$ & $\begin{array}{c}-0.025^{\star \star \star} \\
(0.008)\end{array}$ & $\begin{array}{c}-0.101^{\star \star \star} \\
(0.017)\end{array}$ & $\begin{array}{c}-0.110 * \star \star \\
(0.017)\end{array}$ \\
\hline Friday13 & $\begin{array}{l}-0.022^{*} \\
(0.016)\end{array}$ & $\begin{array}{l}-0.025 \\
(0.020)\end{array}$ & $\begin{array}{c}-0.024 \\
(0.020)\end{array}$ & $\begin{array}{c}-0.158^{* * *} \\
(0.046)\end{array}$ & $\begin{array}{l}-0.088^{\star} \\
(0.046)\end{array}$ \\
\hline $\begin{array}{l}\text { Observa- } \\
\text { tions }\end{array}$ & 4,383 & 4,383 & 4,383 & 4,383 & 4,382 \\
\hline $\begin{array}{l}\text { Number of } \\
\text { births }\end{array}$ & $5,377,308$ & $2,643,160$ & $2,540,842$ & 239,447 & 225,445 \\
\hline $\begin{array}{l}\text { R-squared } \\
\text { Mother }\end{array}$ & $\begin{array}{l}0.915 \\
\text { White }\end{array}$ & $\begin{array}{l}0.781 \\
\text { White }\end{array}$ & $\begin{array}{l}0.775 \\
\text { White }\end{array}$ & $\begin{array}{l}0.855 \\
\text { White }\end{array}$ & $\begin{array}{r}0.870 \\
\text { White }\end{array}$ \\
\hline Birth & $\begin{array}{c}\text { All } \\
\text { Births }\end{array}$ & Boys & Girls & $\begin{array}{l}\text { Kepeat } \\
\text { CS-Boy }\end{array}$ & $\begin{array}{l}\text { Repeat } \\
\text { CS-Girl }\end{array}$ \\
\hline
\end{tabular}

All models include year, month, and day of the week fixed effects and main holiday effects.

Robust standard errors in parentheses.

${ }^{\star * *} p<0.01,{ }^{* *} p<0.05,{ }^{*} p<0.1$

In Table 3 we show that most of the 13 avoidance is concentrated among mothers with greater than a high school education. The coefficient on the interaction term of mother having more than a high school education and birth occurring on the 13th is consistently negative and large in magnitude (second row from bottom of Table 3). In contrast, 8-seeking (4-avoidance) does not seem to be concentrated among more or less educated Chinese.

The California natality data also report the individual hour and minute of birth, which national data on births from NCHS data do not. In results not included, we do not find any evidence of shifting of the time of day of the birth for either the hour or minute of birth (relative to Whites). Such precise birth timing might be more difficult for parents to control than birth date.

We also run a similar regression to 1 , but augmented with a coefficient for month8xday8. However, we do not see a consistent pattern in the point 
estimates and for the Chinese, they are imprecise.

Finally, we investigate whether male Chinese births are mainly driven by Chinese-Chinese couples. We find no evidence of this pattern. We cannot, for example reject the hypothesis that the coefficients on Contains 8 using the main sample (presented in Table 1) and only Chinese-Chinese couples are the same for subsample of sons. We also looked for heterogeneity by whether the mom 185 was born in China and we did not find a substantial difference. It appears that China-born moms respond just as strongly (if not more strongly) to the 13th, but not anymore strongly to the 8th/4th. 


\section{Discussion}

Superstitious preferences have also been shown in other "life" decisions 
financial costs incurred by having a (repeat) C-section versus vaginal delivery.

To our surprise, mothers with more education were more likely to avoid Friday the 13th delivery. On one hand, we may expect more educated mothers to be less superstitious. However, all else being equal, more educated mothers maybe more likely to request and obtain specific dates for scheduled C-sections if they are more likely to be aware of the ability to make such requests, have greater rapport with their physicians, or have more flexible health insurance coverage. Nevertheless, we do not know whether maternal education has a causal effect on adherence to this superstition, or instead something correlated with education (e.g. rapport with obstetrician) accounts for the heterogeneity.

The magnitude of the effects we estimate suggest that the vast majority of Chinese in California do not time births to have auspicious birth dates. Likewise, the literature on sex preference among Asian immigrants finds most do not select sex. That said, Chinese sons delivered by repeat C-section in California are particularly likely to have their delivery date skewed by cultural superstition.

Finally, the magnitude of date shifting among boys underestimates the magnitude of son preference to the extent that not all Chinese parents subscribe to birth date superstition, know that birth dates can be shifted, find an obstetrician who will implement their shifting request, etc. That said, the various manifestations of son preference that parents find more costly than date shifting would tend to show a smaller response than date shifting, other things equal.

An excellent avenue for future research is to analyze whether the difference in birth timing for boys and girls exist even in earlier years when ultrasounds to determine gender were not common. Unfortunately our CA data do not stretch back that far. Future research will explore whether the early years of the national natality data report exact date of birth in order to analyze this hypothesis. 
The data used in this paper can be accessed by submitting an application to the California Office of Statewide Health Planning and Development http : //www.oshpd.ca.gov/HID/Data_Request_Center/. Please see Almond and Doyle (2011) for additional dataset information. Financial support from the National Science Foundation CAREER Award \#SES-0847329 is gratefully acknowledged (Almond). All opinions reflected in this article and any remaining errors are our own. 


\section{Appendix}

Table A1: Regression Estimates: Number of Chinese Births by Day

\begin{tabular}{lccccc}
\hline \hline & $(1)$ & $(2)$ & $(3)$ & $(4)$ & $(5)$ \\
\hline Contains8 & $0.801^{\star \star \star}$ & $0.692^{\star \star \star}$ & 0.115 & $0.208^{\star \star \star}$ & $0.0881^{\star}$ \\
& $(0.308)$ & $(0.216)$ & $(0.209)$ & $(0.0557)$ & $(0.0532)$ \\
Contains4 & -0.460 & -0.00735 & $-0.386^{\star}$ & $-0.104^{\star}$ & -0.0758 \\
& $(0.316)$ & $(0.222)$ & $(0.214)$ & $(0.0572)$ & $(0.0546)$ \\
Thirteen & $-1.883^{\star \star \star}$ & $-0.740^{\star}$ & $-0.991^{\star \star \star}$ & $-0.174^{\star}$ & $-0.274^{\star \star \star}$ \\
& $(0.552)$ & $(0.388)$ & $(0.374)$ & $(0.0999)$ & $(0.0953)$ \\
Friday13 & -1.450 & -1.304 & -0.167 & $-0.566^{\star \star}$ & $-0.573^{\star \star}$ \\
& $(1.476)$ & $(1.037)$ & $(1.000)$ & $(0.267)$ & $(0.255)$ \\
\hline Observa- & 4,383 & 4,383 & 4,383 & 4,383 & 4,383 \\
tions & 0.256 & 0.158 & 0.148 & 0.105 & 0.087 \\
R-squared & Chinese & Chinese & Chinese & Chinese & Chinese \\
Mother & All & Boys & Girls & Repeat & Repeat \\
Birth & Births & & & CS-Boy & CS-Girl
\end{tabular}

All models include year, month, and day of the week fixed effects and main holiday effects.

Robust standard errors in parentheses.

${ }^{\star * *} \mathrm{p}<0.01,{ }^{* *} \mathrm{p}<0.05,{ }^{*} \mathrm{p}<0.1$ 
Table A2: Regression Estimates: Number of White Births by Day

\begin{tabular}{lccccc}
\hline \hline & $(1)$ & $(2)$ & $(3)$ & $(4)$ & $(5)$ \\
\hline Contains8 & 2.827 & 1.137 & 2.116 & -0.289 & 0.384 \\
& $(2.780)$ & $(1.747)$ & $(1.673)$ & $(0.473)$ & $(0.456)$ \\
Contains4 & $6.118^{\star \star}$ & 2.079 & $4.363^{\star \star}$ & 0.402 & 0.608 \\
& $(2.853)$ & $(1.793)$ & $(1.717)$ & $(0.486)$ & $(0.468)$ \\
Thirteen & $-27.37^{\star \star \star}$ & $-11.31^{\star \star \star}$ & $-14.94^{\star \star \star}$ & $-6.019^{\star \star \star}$ & $-5.578^{\star \star \star}$ \\
& $(4.983)$ & $(3.131)$ & $(2.999)$ & $(0.848)$ & $(0.818)$ \\
Friday13 & $-31.49^{\star \star}$ & $-17.21^{\star \star}$ & $-16.25^{\star \star}$ & $-10.46^{\star \star \star}$ & $-6.265^{\star \star \star}$ \\
& $(13.32)$ & $(8.372)$ & $(8.019)$ & $(2.268)$ & $(2.186)$ \\
\hline Observa- & 4,383 & 4,383 & 4,383 & 4,383 & 4,383 \\
tions & 0.915 & 0.868 & 0.867 & 0.822 & 0.828 \\
R-squared & White & White & White & White & White \\
Mother & All & Boys & Girls & Kepeat & Kepeat \\
Birth & Births & & & CS-Boy & CS-Girl \\
& & &
\end{tabular}

All models include year, month, and day of the week fixed effects and main holiday effects.

Robust standard errors in parentheses.

${ }^{\star * \star} p<0.01,{ }^{* *} p<0.05,{ }^{*} p<0.1$

\section{References}

Abrevaya, J., 2009. Are there missing girls in the United States? Evidence from birth data. American Economic Journal: Applied Economics 1, 1-34.

Almond, D., Chay, K.Y., Lee, D.S., 2005. The costs of low birth weight. The Quarterly Journal of Economics 120, 1031-1084.

Almond, D., Doyle, J.J., 2011. After midnight: A regression discontinuity design in length of postpartum hospital stays. American Economic Journal: Economic Policy 3, 1-34. URL: http://www.aeaweb.org/articles.php?doi= 10.1257/pol.3.3.1, doi:10.1257/pol.3.3.1.

Almond, D., Edlund, L., 2008. Son biased sex ratios in the 2000 United States census. Proceedings of the National Academy of Sciences (PNAS) 105, 56815682. 
Bauer, T.K., Bender, S., Heining, J., Schmidt, C.M., 2013. The lunar cycle, sunspots and the frequency of births in Germany, 1920-1989. Economics \& Human Biology 11, 545 - 550. URL: http://www.sciencedirect. com/science/article/pii/S1570677X12001311, doi:http://dx.doi.org/ 10.1016/j.ehb.2012.11.001.

Currie, J., Schwandt, H., 2013. Within-mother analysis of seasonal patterns in health at birth. Proceedings of the National Academy of Sciences 110, 12265-12270. URL: http://www.pnas. org/content/110/30/12265.abstract, doi:10.1073/pnas.1307582110, arXiv:http://www.pnas.org/content/110/30/12265.full.pdf+html.

Dickert-Conlin, S., Chandra, A., 1999. Taxes and the timing of births. Journal of Political Economy 107, 161-177.

Do, Q.T., Phung, T.D., 2010. The importance of being wanted. American Economic Journal: Applied Economics 2, 236-53. URL: http://www.aeaweb. org/articles.php?doi=10.1257/app.2.4.236, doi:10.1257/app.2.4.236.

Dubuc, S., Coleman, D., 2007. An increase in the sex ratio of births to Indiaborn mothers in England and Wales: Evidence for sex-selective abortion. Population and Development Review 33, 383-4000.

Ecker, J., 2013. Elective cesarean delivery on maternal request. JAMA 309, 1930-1936. URL: +http://dx.doi.org/10.1001/jama.2013.3982, doi:10. 1001/jama.2013.3982.

Fortin, N.M., Hill, A.J., Huang, J., 2014. Superstition in the housing market. Economic Inquiry 52, 974-993. URL: http://dx.doi.org/10.1111/ecin. 12066, doi:10.1111/ecin.12066.

Gans, J.S., Leigh, A., 2009. Born on the first of july: An (un)natural experiment in birth timing. Journal of Public Economics 93, 246 - 263. URL: http://www.sciencedirect.com/science/article/pii/ 
S0047272708001217, doi:http://dx.doi.org/10.1016/j.jpubeco.2008. 07.004 .

Gans, J.S., Leigh, A., 2012. Bargaining over labour: Do patients have any power?*. Economic Record 88, 182-194. URL: http://dx.doi.org/10.1111/j.1475-4932.2011.00776.x, doi:10.1111/ j.1475-4932.2011.00776.x.

Gans, J.S., Leigh, A., Varganova, E., 2007. Minding the shop: The case of obstetrics conferences. Social Science \& Medicine 65, 1458 - 1465. URL: http://www.sciencedirect.com/science/article/ pii/S0277953607003176, doi:http://dx.doi.org/10.1016/j.socscimed. 2007.05.034.

Goodkind, D., 1996. Chinese lunar birth timing in singapore: New concerns for child quality amidst multicultural modernity. Journal of Marriage and Family 58, pp. 784-795. URL: http://www.jstor.org/stable/353736.

Kaku, K., Matsumoto, Y.S., 1975. Influence of a folk superstition on fertility of japanese in California and Hawaii, 1966. American Journal of Public Health $65,170-74$.

Lam, D., Miron, J., 1991. Seasonality of births in human populations. Social Biology 38, 51-78.

Levy, B.R., Chung, P.H., Slade, M.D., 2011. Influence of valentine's day and halloween on birth timing. Social Science \& Medicine 73, 1246 - 1248. URL: http://www.sciencedirect.com/science/article/ pii/S0277953611004485, doi:http://dx.doi.org/10.1016/j.socscimed. 2011.07.008.

Lin, H.C., Xirasagar, S., Tung, Y.C., 2006. Impact of a cultural belief about ghost month on delivery mode in taiwan. Journal of Epidemiology and Community Health 60, 522-526. URL: http: 
//jech.bmj.com/content/60/6/522.abstract, ～doi:10.1136/jech.2005. 041475, arXiv:http://jech.bmj.com/content/60/6/522.full.pdf+html.

Lo, J.C., 2003. Patients attitudes vs. physicians determination: implications for cesarean sections. Social Science \& Medicine 57, 91 - 96. URL: http: //www.sciencedirect.com/science/article/pii/S0277953602003015, doi:http://dx.doi.org/10.1016/S0277-9536(02)00301-5.

McKinnish, T., Rees, D.I., Langlois, P.H., 2014. Seasonality in birth defects, agricultural production and urban location. Economics \& Human Biology 15, 120 - 128 . URL: http://www.sciencedirect. com/science/article/pii/S1570677X14000689, doi:http://dx.doi.org/ 10.1016/j.ehb.2014.08.001.

Miller, J.G., 2014. Revisiting the valentine's day and halloween birth timing phenomenon. Manuscript, Pomona College Department of Economics.

Minkoff, H., Chervenak, F.A., 2003. Elective primary cesarean delivery. New England Journal of Medicine 348, 946-950. URL: http://www. nejm.org/doi/full/10.1056/NEJMsb022734, doi:10.1056/NEJMsb022734, arXiv:http://www.nejm.org/doi/pdf/10.1056/NEJMsb022734. pMID: 12621140.

Rohlfs, C., Reed, A., Yamada, H., 2010. Causal effects of sex preference on sexblind and sex-selective child avoidance and substitution across birth years: Evidence from the Japanese year of the fire horse. Journal of Development Economics 92, 82-95. URL: http://ideas.repec.org/a/eee/deveco/ v92y2010i1p82-95.html.

Schulkind, L., Shapiro, T.M., 2014. What a difference a day makes: Quantifying the effects of birth timing manipulation on infant health. Journal 345 of Health Economics 33, 139 - 158. URL: http://www.sciencedirect. com/science/article/pii/S0167629613001458, doi:http://dx.doi.org/ 10.1016/j.jhealeco.2013.11.003. 
Tita, A.T., Landon, M.B., Spong, C.Y., Lai, Y., Leveno, K.J., Varner, M.W., Moawad, A.H., Caritis, S.N., Meis, P.J., Wapner, R.J., Sorokin, Y., 350 Miodovnik, M., Carpenter, M., Peaceman, A.M., O'Sullivan, M.J., Sibai, B.M., Langer, O., Thorp, J.M., Ramin, S.M., Mercer, B.M., 2009. Timing of elective repeat cesarean delivery at term and neonatal outcomes. New England Journal of Medicine 360, 111-120. URL: http://www.nejm.org/doi/full/ 10.1056/NEJMoa0803267, doi:10.1056/NEJMoa0803267. pMID: 19129525. 